\title{
Reflections on the Role of Malatl in Gynecological Cancer
}

This article was published in the following Dove Press journal:

Cancer Management and Research

\author{
Huiyan Liao' \\ Qi Chen ${ }^{2}$ \\ Jing $\mathrm{Xiao}^{3}$
}

'The 2nd Clinical College of Guangzhou University of Chinese Medicine, Guangzhou, Guangdong Province 510006, People's Republic of China; ${ }^{2}$ The 6th Clinical College of Guangzhou University of Chinese Medicine, Guangzhou, Guangdong Province 510006, People's Republic of China; ${ }^{3}$ Department of Gynecology, the University Town Branch, the Second Affiliated Hospital of Guangzhou University of Chinese Medicine, Guangzhou, Guangdong Province 510120, People's Republic of China
Correspondence: Jing Xiao Department of Gynecology, the University Town Branch, the Second Affiliated Hospital of Guangzhou University of Chinese Medicine, Guangzhou, Guangdong Province 510120, People's Republic of China Tel +86 I3556|483I8

Email xiaojingson_2004@I26.com

\begin{abstract}
Non-coding RNAs (ncRNAs) have received significant attention over the last few years. Malat1, as one of the most extensively studied ncRNAs, is believed to be not only a potential biomarker for disease diagnosis and prognosis, but also a candidate drug target for gynecological cancers. This potential is supported by a growing body of experimental evidence demonstrating that Malat 1 participates in the occurrence, progression, and metastasis of tumors. Research has also shown that Malat1 can influence patient survival by regulating a range of target genes and signaling pathways. However, previous review articles have generally failed to consider the role of Malat1 in gynecological cancer in detail. In the present review, we summarize recent progress in research relating to the clinical relevance of Malat1 and the molecular mechanisms underlying the action of this ncRNA. Besides, we put forward some action points for further research after taking into consideration the sublocation and other essential properties of Malat1, which might enable us to have a better understanding of the potential of this molecule regarding clinical diagnosis and treatment.
\end{abstract}

Keywords: Malat1, gynecological cancer, LncRNA, molecular functions, biomarkers, therapeutic targets

\section{Introduction}

Over recent years, the depth and coverage of sequencing technology has improved significantly. These developments have led to the discovery of an increasing number of full-length non-coding RNA (ncRNA) sequences and their spliced transcript variants. Research has shown that long ncRNA (lncRNA) performs a myriad of functions, from building up whole chromosomes and acting as a regulator of gene transcription to acting as a template for the translation of protein sequences. ${ }^{1}$

Similarly, improvements in medical technology have led to significant improvements in the early detection and treatment of gynecological cancers - cancers start in a woman's reproductive organs, which will benefit for overall survival of patients; however, there are still some limitations associated with these techniques. There is an urgent need to identify more accurate molecular markers and more efficient therapeutic targets in order to bring further hope to the patients who suffer from this often-untreatable disease. Over recent years, an increasing number of research studies have shown that the abnormal expression and function of Malat1, a lncRNA, is associated with several forms of gynecological cancer.

Malat1 is one of the more well-known $\operatorname{lncRNAs}{ }^{2}$ and has been studied in greater detail than many of the other lncRNAs. Previous research has focused on gynecological cancers enough, but few studies has sorted out the potential roles of Malat1 in this field exclusively 
and in detail as far as we are concerned. In this review, we aimed to describe the structure of Malat1, its potential role as a potential biomarker and therapeutic target, and discuss its mechanism of action in the context of gynecological cancers.

\section{Search Strategy and Selection Criteria}

We performed literature searches using the PubMed and Embase databases between January 1st, 2000 and June 31st, 2020 using the following search terms: "Malat1," "NEAT2," "cancer," and "neoplasm." Studies were included when they satisfied the following inclusion criteria: (1) written in English; (2) original article; (3) focusing on gynecological cancers. We excluded letters, comments and case reports.

\section{The Structure and Function of Malat I}

The structure of the lncRNA that is newly transcribed by the Malat1 gene is very similar to transfer RNA (tRNA) at the 3'end and can be cleaved by ribozyme RNase P (RNase P) and RNase Z; thus, causing its release into the cytoplasm. The remaining element for nuclear expression (ENE) motif at the 3 'end forms a stable triple helix. In this way, this RNA molecule grows to become a mature one (Figure 1). ${ }^{3}$

The mature Malat1 lncRNA is structurally stable and cannot be cleaved easily; ${ }^{4}$ this is due to the presence of the triple helix at the $3^{\prime}$ end. ${ }^{5}$ The stability of this structure has been proven to be associated with its ability to undergo fine dynamic tuning. ${ }^{6}$ Peripheral structural elements, such as certain RNAs, play important roles in regulating the dynamics and stability of the triple helix.

It has also been reported that the mature Malat1 IncRNA is eventually enriched in nuclear speckles which is a place for splicing factor storage and modification. ${ }^{3}$ This process may be promoted by a short interspersed nuclear element (SINE) in Malat1; this element facilitates interaction with other proteins, such as HNRNPK which is capable of driving the retention of RNA in the nucleus. ${ }^{7}$

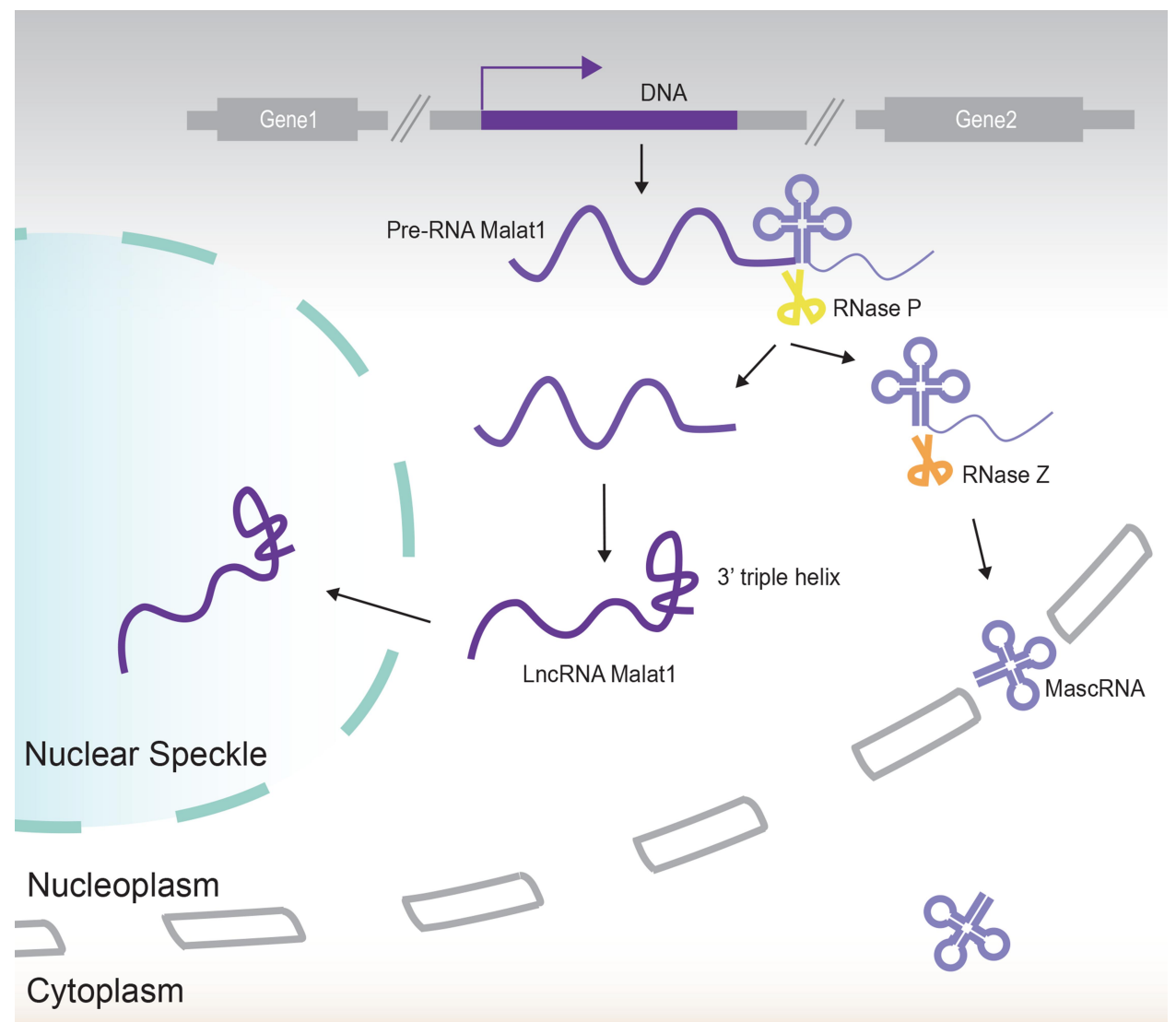

Figure I The formation and maturation of Malatl. Malatl is a typical long intergenic non-coding RNA (lincRNA) that is transcribed from the intergenic regions of protein coding genes. The Malatl pre-RNA has a tRNA-like structure at its 3'end which can be cleaved by ribozyme RNase P and RNase Z. The tRNA-like molecule, referred to as "mascRNA" is subsequently released into the cytoplasm. The remaining molecule grows to maturity to form a triple-helix structure at its 3 'end and relocates to nuclear speckles. 
The Malat1 lncRNA is a trans-acting element and often needs to be relocated from the site of synthesis in order to exert impact on gene regulation. ${ }^{8}$ Furthermore, according to a recent study, Malat1 can also serve as a circular RNA (circRNA); this form of RNA is produced by the backsplicing of IncRNA Malat1, locates exclusively in the cytoplasm rather than in the nucleus, and plays a role in post-transcriptional regulation. ${ }^{9}$

Malat1 is expressed at high levels in human cells; this implies that this molecule plays an important role in maintaining normal physiological and pathological processes that may affect the function and metabolism of cells in various ways. It has been reported that Malat1 participates in the process of cell functional regulation at the transcriptional and post-transcriptional levels via direct and indirect interactions with DNA, RNA, and functional proteins (Figure 2). ${ }^{10-14} \mathrm{~A}$ large number of studies have confirmed that Malat1 can regulate multiple cellular processes, including proliferation, invasion, metastasis, and apoptosis, and the expression of Malat1 has been correlated with a wide range of cancers, ${ }^{15}$ including immunological, ${ }^{16,17}$ cardiovascular, $^{18,19}$ endocrine, ${ }^{20,21}$ hematological, ${ }^{22,23}$ neurological, ${ }^{24,25}$ and many other forms of cancer. ${ }^{26,27}$

\section{The Clinical Relevance of Malat I in Gynecological Malignancies \\ Malat I as a Biomarker}

It is highly evident that early diagnosis has a positive effect on the prognosis of patients with tumors. However, there are many forms of gynecological cancers, such as ovarian cancer, which lack an effective method for the universal screening. According to recent research, Malat1 is differentially expressed in the tissues and secretions (such as cervicovaginal lavage) when compared between cancerous and non-cancerous individuals. Consequently, Malat1 may hold potential as an effective biomarker.

\section{Cervical Cancer}

According to global statistics, cervical cancer is the fourth most common form of cancer in women; ${ }^{28}$ approximately $85 \%$ of this population reside in developing countries where cervical cancer is a leading cause of female mortality. ${ }^{29}$ Persistent high-risk human papillomavirus (rhHPV) infection is the main cause of cervical cancer. It is possible that Malat1 serve as a marker to predict HPV infection because it is expressed at higher levels in HPVpositive tissues compared to tissues that are HPVnegative. ${ }^{30}$ Malat1 could also serve as a predictor for cervical cancer, because it is expressed at high levels in tissues and exosomes that have been separated from cervicovaginal lavage samples ${ }^{30}$ when compared with nontumor samples.

The application of multivariate analyses in combination with the Cox proportional hazards model has previously shown that the expression level of Malat1 is an independent predictor for overall survival (OS). Furthermore, the expression levels of Malat1 are correlated with tumor size, International stage defined by Federation of Gynecology and Obstetrics (FIGO), vascular invasion, and lymph node metastasis. ${ }^{31}$ When compared to tissues that are sensitive to radiotherapy, the levels of Malat1 are significantly elevated in tissues that are resistant to radiotherapy. ${ }^{32}$

\section{Ovarian Cancer}

Ovarian cancer involves several histopathological entities; the most prevalent form is high-grade serous ovarian cancer (HGSOC), a type of epithelial ovarian cancer (EOC). ${ }^{33,34}$ This particular form of ovarian cancer is the leading cause of death from gynecological cancer in the United States and is the country's fifth most common cause of cancer mortality in women. ${ }^{35}$

In patients with ovarian cancer, a higher expression level of Malat1 in either local lesions ${ }^{36}$ or serum exosome $^{37}$ may indicate a poorer prognosis. When estimated by survival curves, the higher the expression of Malat1, the poorer the overall survival and progressionfree survival (PFS) of patients with ovarian cancer will be. ${ }^{36}$ Furthermore, receiver operating characteristic (ROC) analysis indicates that plasma levels of Malat1 can generate an area under the curve (AUC) that effectively distinguishes between EOC with metastasis and EOC without metastasis. ${ }^{38}$ In addition, patients with recurrent HGSOC exhibit a high frequency of Malat1 involvement with fusion genes. ${ }^{39}$ In conclusion, Malat1 shows strong potential as a prognostic biomarker for ovarian cancer.

\section{Endometrial Carcinoma}

Global statistics show that endometrial cancer (EC) is a common malignancy of the female genital tract. Although this disease is more likely to be discovered at an early and treatable stage, some data show that the mortality rate for endometrial cancer has increased more rapidly than the incidence rate. ${ }^{40}$ Single nucleotide polymorphisms (SNPs) in Malat1 DNA, such as Rs664589C $>$ G, have been shown to significantly 


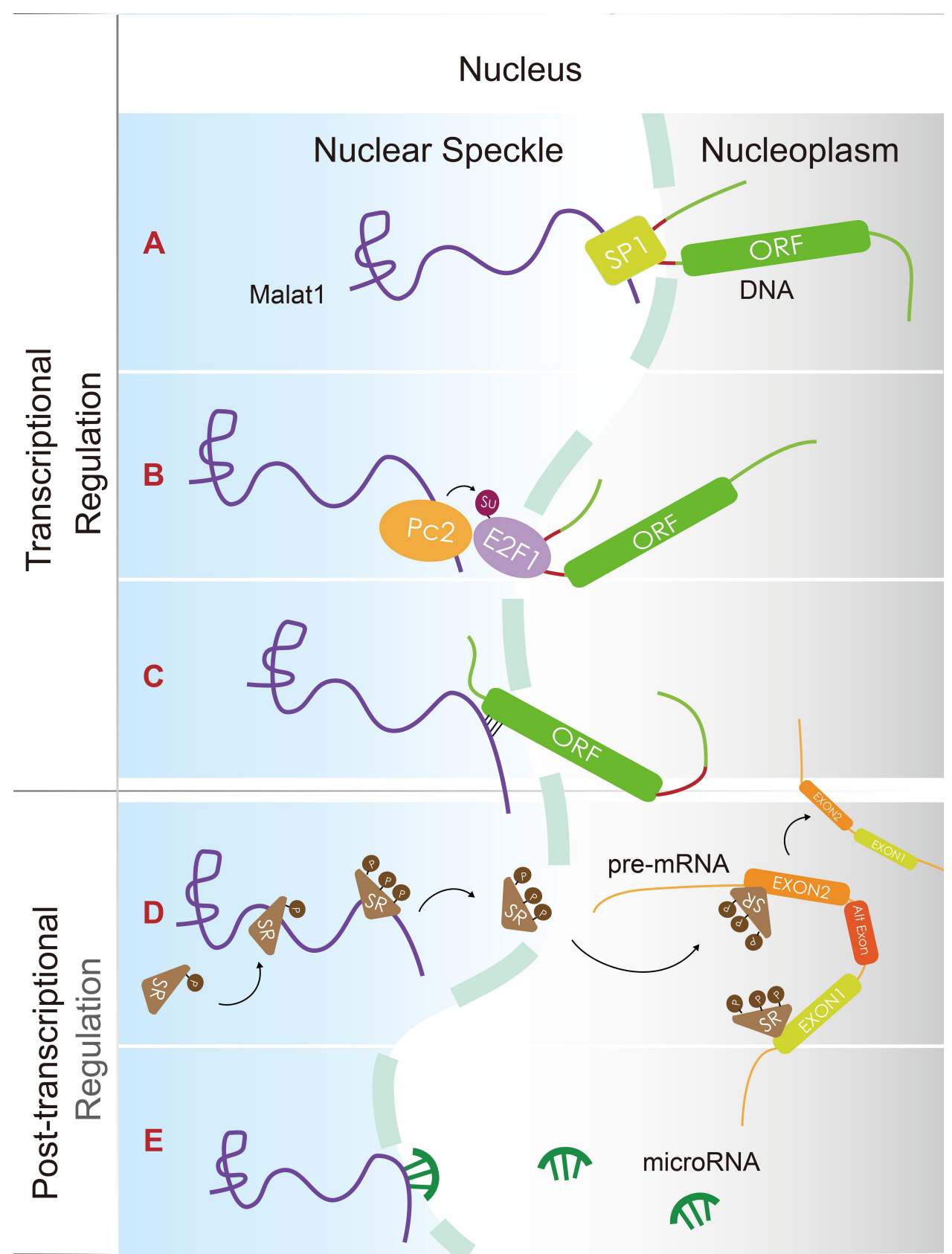

Figure 2 Malat I regulates gene expression at the transcriptional and post-transcriptional level. (A) Malatl recruits the SpI transcriptional factor to the LTBP3 promotor to enhance the transcription of LTBP3. (B) By binding to unmethylated Pc2, Malatl promotes the SUMOylation of the E2FI transcriptional factor, thus activating the transcription of target genes. (C) Malatl can directly localize DNA at specific transcribed loci, such as the transcriptional termination site (TTS) and serves as scaffolds that bind proteins to interact with DNA. (D) Malat I regulates the levels of phosphorylated serine/arginine (SR) splicing factor; this improves the range of alternative splicing (AS) towards pre-mRNAs. (E) Malatl binds competitively with some microRNAs to regulate the translation of certain mRNAs that share the same RNA-binding sites (MREs).

increase the risk of endometrial cancer when tested in tissue samples and peripheral blood and following the application of logistic regression analyses. ${ }^{41}$ In addition, the expression levels of Malat1 have been found to be related to tumor type, metastatic lymph nodes, and recurrence rate. ${ }^{42}$

\section{Vulvar Cancer}

Though cancer of the vulva is a rare disease, ${ }^{43}$ the incidence of vulvar squamous cell carcinoma (VSCC) has increased in Western countries over the last few decades. ${ }^{44}$ Malat1 may represent a potential diagnostic biomarker for VSCCs; previous research involving ROC 
analysis can generate an ideal AUC when distinguishing cancerous and non-cancerous tissues. ${ }^{45}$

\section{Malat I as a Potential Therapeutic Target} Improving Therapeutic Resistance

Radiotherapy and chemotherapy play a significant role in the treatment of gynecological cancers. However, a substantial number of patients show resistance to these forms of therapy. Silencing RNA (Si-Malat1) has been shown to modulate the radiosensitivity of high-risk human papillomavirus (hr-HPV) positive cervical cancer $^{46}$ and increase sensitivity to cisplatin, at least to a certain extent. ${ }^{47}$ The knockdown of Malat1 has also been shown to reverse resistance to cisplatin in cases of cisplatin-resistant ovarian cancer. ${ }^{48}$ Consequently, drugs that specifically target Malat1 could be useful when applied simultaneously with radiotherapy and chemotherapy.

\section{Modulating the Disease Process}

An increasing number of drugs that are used to treat tumors, including those already on the market and those under development, have been proven to act on Malat1, at least to a certain extent. For example, casiopeina II-gly ${ }^{49}$ and metformin $^{50}$ are both used to treat cervical cancer and act by modulating the expression of Malat1. Furthermore, rosmarinic acid has been shown to induce potent effects against ovarian cancer cells by modulating the expression of Malat $1 .{ }^{51}$

It would therefore be very worthwhile to develop new drugs that are capable of modulating the expression levels of Malat1. A recent study described the successful downregulation of Malat1 both in vivo and in vitro, thus suggesting that Malat1 represents an ideal target for cervical cancer, ${ }^{31,52}$ ovarian cancer, ${ }^{36,53}$ and choriocarcinoma. ${ }^{54,55}$

The direct targeting of Malat1 has some distinct advantages. Firstly, selective small molecule inhibitors offer the potential to potently antagonize the intended target while minimizing off-target inhibition that might lead to dose reduction or intolerable side-effects. ${ }^{56}$ Secondly, previous studies show that Malat1 is the upstream regulator of many cancer-related proteins. The inhibition of Malat1 may regulate these proteins simultaneously, which means that tumor progression may be prevented via several different biological processes, thus reducing the risk of acquired drug resistance.

This realization of this concept is possible due to significant developments in genetic engineering. For example, the targeted genetic deletion of Malat1 by zinc finger nucleases ${ }^{57}$ and synthetic oligonucleotides designed to Malat1 as a therapeutic target, including siRNAs and locked nucleic acid (LNA) gapmer antisense oligonucleotides (ASOs), ${ }^{58-60}$ are worthy of consideration.

\section{The Mechanistic Effects of Malat I in Gynecological Malignancies}

\section{Cervical Cancer}

It is well-known that the main cause of cervical cancer is persistent rhHPV infection. The knockdown of E6 and E7, crucial oncogenes for rhHPV, has been shown to reduce the expression of Malat $1,{ }^{61}$ thus demonstrating that Malat1 may participate in the mechanism by which HPV proteins can induce cancer.

The upregulation of Malat1 has been shown to be related to increased cell growth and invasion, and reduced levels of apoptosis. ${ }^{52}$ The mechanisms underlying these effects include the competitive binding of Malat1 with microRNAs, the modification of specific proteins involved in translation, and protein interactions. In a previous report, Xia et al claimed that by competitively binding with miR142-3p, Malat1 gained the capability to increase the levels of HMGA2, a known oncogene. ${ }^{50}$ Malat1 can also act as a ceRNA and modulate the expression of FZD2 by binding to miR-17-5p, thus resulting in the activation of the Wnt signaling pathway. ${ }^{49}$ In addition, Malat1 is also known to interact with miR124, ${ }^{62}$ miR625-5p, ${ }^{63}$ and other miRNAs that are known to be related to the development of tumors (Table 1). With regards to the alternative splicing process, it is possible that Malat1 may regulate alternative splicing (AS) by modulating the levels of phosphorylated SR proteins. ${ }^{14}$ In a previous study, Liu and colleagues found that the combination of Malat 1 and unmethylated Pc2 can promote the SUMOylation of E2F1, thus leading to the activation of a series of growth-control gene program. ${ }^{64}$

\section{Ovarian Cancer}

It has been reported that increased expression levels of Malat1 are associated with the viability, proliferation, invasion, and migration of ovarian cancer cells. ${ }^{65}$ The precise mechanisms responsible for these effects have yet to be fully determined, although research has shown that Malat1 appears to exert a positive impact on several wellknown pathways, including the PI3K/AKT, Wnt/betacatenin, and MAPK pathways. ${ }^{66,67}$ Malat1 is capable of competitively binding with miR506 and then increasing 
Table I MalatI Interacts with Certain microRNAs in Gynecological Cancers

\begin{tabular}{|c|c|c|c|c|c|}
\hline Disease & Related Molecules & Model & Expression & Functional Phenotypes & Ref \\
\hline \multirow[t]{6}{*}{$\mathrm{CC}$} & Malat I/miR-I43 & Tissue; in vitro & Up & $\begin{array}{l}\text { Promotes cell survival; reduces apoptosis, cell cycle arrest, } \\
\text { radiotherapy efficiency }\end{array}$ & [32] \\
\hline & Malat I/miR-I45 & Tissue; in vitro & Up & Promotes radio-resistance, cell viability; reduces apoptosis & [46] \\
\hline & Malat I/miR-17-5p/FZD2 & $\begin{array}{l}\text { Bioinformatics; } \\
\text { tissue; in vitro }\end{array}$ & Up & Promotes cell viability; reduces apoptosis & [49] \\
\hline & Malat I/miR-142-3p & $\begin{array}{l}\text { Tissue; in vitro, } \\
\text { in vivo }\end{array}$ & Up & Promotes migration and invasion & [50] \\
\hline & Malat I/miR-124/RBG2 & Tissue; in vitro & $U_{p}$ & Promotes cancer cell growth, invasion; reduces apoptosis & [62] \\
\hline & Malat I/miR-625-5p/NF-кB & Tissue; in vitro & Up & Promotes cell growth & [63] \\
\hline \multirow[t]{4}{*}{ OC } & $\begin{array}{l}\text { Malat I/miR-503-5p/JAK2- } \\
\text { STAT3 pathway }\end{array}$ & In vitro & Up & Promotes proliferation; reduces apoptosis & [53] \\
\hline & Malat I/miR-506/iASPP & Tissue; in vitro & Up & Promotes cell growth & [68] \\
\hline & Malat I/miR-2I I/PHFI9 & $\begin{array}{l}\text { Tissue; in vitro; } \\
\text { in vivo }\end{array}$ & Up & $\begin{array}{l}\text { Promotes cell proliferation, migration, and xenograft } \\
\text { growth and reduces cell apoptosis }\end{array}$ & [69] \\
\hline & Malat I/miR-200c & Tissue; in vitro & Up & Promotes cell viability, migration and invasion & [70] \\
\hline EC & TGF- $\beta /$ MALATI/miR-200c & $\begin{array}{l}\text { Tissue; in vivo; } \\
\text { in vitro }\end{array}$ & Up & Promotes invasion and migration, EMT & [72] \\
\hline GTN & Malat I/miR-218/Fbxw8 & In vivo; in vitro & Up & Promotes cell growth; reduces growth arrest & [54] \\
\hline
\end{tabular}

Note: Table shows a summary of model, expression, and functional phenotypes in gynecological cancer.

Abbreviations: CC, cervical cancer; OC, ovarian cancer; EC, endometrial carcinoma; GTN, gestational trophoblastic neoplasia; EMT, epithelial-mesenchymal transition.

the expression of iASPP, a well-known oncogene. ${ }^{68}$ Malat1 can also act directly as a molecular sponge for miR211, thus regulating PHF19-mediated cell growth and progression. $^{69}$ In addition, studies have suggested that Malat1 can also combine with miR200c, ${ }^{70}$ miR142$3 \mathrm{p},{ }^{36}$ and miR-503-5p. ${ }^{53}$ Apart from interacting with various microRNAs, the activity of Malat1 has also been reported to elevate the levels of RBFOX2, a splicing factor that targets KIF1B, a pro-apoptotic tumor suppressor gene. Furthermore, the suppression of MALAT1 resulted in the reduced expression of $\mathrm{RBFOX} 2$ and the alternative processing of KIF1B. ${ }^{71}$ The suppression of RBFOX2 induces the preferential splicing of the pro-apoptotic isoform of KIF1B (KIFB1B-beta) and activates anoikis which is also known as suspension-induced apoptosis. ${ }^{71}$

\section{Endometrial Carcinoma}

Previous research has shown that Malat1 affects the proliferation, migration, and apoptosis of endometrial cancer cells. For example, $\mathrm{Li}$ et al discovered that the TGF- $\beta$ oncogene lies upstream of the Malat1-miR200c axis and the combination of Malat1 shRNA and TGF- $\beta$ added into the EC cell lines led to changes in epithelial-mesenchymal transition (EMT) that were contrasted directly to the effect of TGF- $\beta$ alone. ${ }^{72}$ The PCDH10-Wnt/b-catenin-MALAT1 regulatory axis may also play an important role in the development of endometrial cancer both in vitro and in vivo. ${ }^{42}$

\section{Gestational Trophoblastic Neoplasia}

Gestational trophoblastic neoplasia is a rare disease and is difficult to treat. ${ }^{73}$ However, by knocking down Malat1 and inhibiting miR-218 in JEG-3 and JAR cells, Shi et al proved that Malat1 might be able to regulate the expression of Fbxw8 protein, an oncogene, and therefore promote cell growth. ${ }^{54}$

In addition, certain studies have identified correlations between Malat1 expression and the onset and development of precancerous cervical lesions, ${ }^{74}$ and vulvar squamous cell carcinoma. ${ }^{45}$ Collectively, these data indicate that abnormalities in the expression of Malatl can play roles in a range of gynecological malignancies.

\section{Discussion and Future Perspectives}

It is evident that ncRNAs are becoming a highly prominent focus of current research activity. ${ }^{75}$ However, despite such research attention, we still know very little about the functional role of the non-coding transcriptome. 
Generally, ncRNAs can be classified into three groups: microRNAs (miRNAs), circular RNAs (circRNAs), and long ncRNAs (lncRNAs). When compared with two other forms of ncRNA, microRNA is generally with less variety and its functional role appears to much simpler; generally, the predominant function of microRNAs is to interact with RNA. ${ }^{76,77}$ This might explain why research tends to focus on the other two forms of ncRNA nowadays. In contrast, research has shown that lncRNAs are able to interact with a range of other molecules in various different ways. For example, lncRNAs can not only combine with DNA or RNA ${ }^{78}$ via the principle of complementary base pairing, but also interact with a range of different proteins. ${ }^{79}$ This array of different combinations allows lncRNAs to perform a range of molecular functions. As a common form of lncRNA, Malat1 has received significant research attention.

\section{Reflections on the Clinical Value of Malat I}

It is commonly accepted that Malat 1 is involved in a variety of physiological and pathological processes related to cancer. The aberrant expression of Malat1, and the presence of deleterious SNPs, have both been shown to be associated with cancer initiation, progression, metastasis, and drug resistance, and can help us to predict the prognosis of patients. In addition, Malat 1 can be detected in exosomes isolated from certain body fluids, including cervicovaginal lavage and serum; this suggests that exosomes that express Malat1 could represent a convenient and non-invasive biomarker for gynecological cancers. ${ }^{80,81}$ The application of exosomal biomarkers would be far more acceptable for patients than other, more invasive, biomarkers. However, the clinical use of exosomes as biomarkers is limited by the extensive processing time required to isolate and detect exosomes. ${ }^{82}$ Fortunately, researchers are now working on micro- and nano-technologies in an attempt to overcome these technical challenges. ${ }^{83}$

The potential clinical use of Malat1 is also supported by rapid developments in medical biotechnology. However, multidisciplinary approaches are still required to elucidate the specific functions of Malat 1 and identify the mechanisms responsible for its functional effects. Moreover, the efficacy of Malat1 as a biomarker has yet to be fully validated in well-designed observational and randomized controlled studies.

\section{Reflections on the Mechanisms Underlying the Actions of Malat I}

It is critical to identify the precise functional roles of Malat1, and understand the mechanisms responsible for these effects, if we are to support the development of Malat1 as a potential diagnostic or therapeutic target for gynecological cancer. ${ }^{84}$ A significant body of research has focused on Malat1 as a ceRNA and its functional role as a molecular sponge. These studies have shown that the Malat1 lncRNA binds competitively to different miRNAs, thus attenuating relationships between microRNAs and certain protein-coding oncogenes. These events can thus lead to the increased expression of oncogenes and may lead to disease onset (Figure 3). ${ }^{85}$

Given our current knowledge of the general biological processes and functions that have been ascribed to ceRNAs thus far, we propose that a range of methodological studies now need to be carried out in order to further enhance our understanding of the Malat1 lncRNA. First, we need to prove whether Malat1 possesses miRNA response elements (MREs). These sites are necessary for Malat1 to be able to combine with certain miRNAs via the principle of complementary base pairing. Moreover, it is necessary to identify the precise number and location of such MREs within the Malat1 sequence. Our knowledge of existing MREs indicates that the functional role of these sites can be influenced by a range of factors, including molecular concentration, subcellular distribution, cell type, and interactions with RNA-binding proteins. ${ }^{85}$ In addition, not all of the MREs that are located on ceRNAs operate in the same manner. Although two MREs may be predicted to bind the same microRNA, it is evident that the binding efficacies involved could vary significantly. ${ }^{86}$ Further studies may involve investigating the specific sequences of the main binding site. Secondly, competitive inhibition should be utilized in a standardized manner. According to our understanding of ceRNAs, altering the expression levels of an individual ceRNA would have repercussions on other ceRNAs that share the same MRE. ${ }^{85}$ Thus, we should not only inhibit/overexpress Malat1 to investigate how the targeted coding gene is altered, but also manipulate the target gene and evaluate the resultant changes in Malat1 expression. This approach has been not commonly adopted in previous gynecological studies. Thirdly, we can increase the rigor of research studies by carrying out rescue experiments involving both Malat1 and miRNA. Now that we know that the expression levels of Malat1 


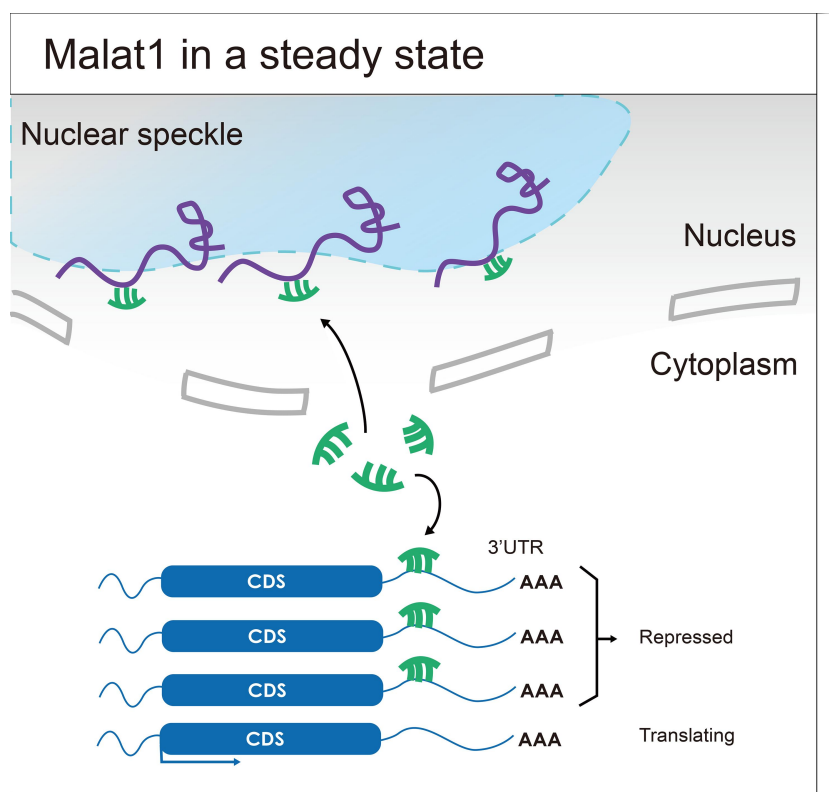

Expression levels

\section{Malat1 overexpressed}

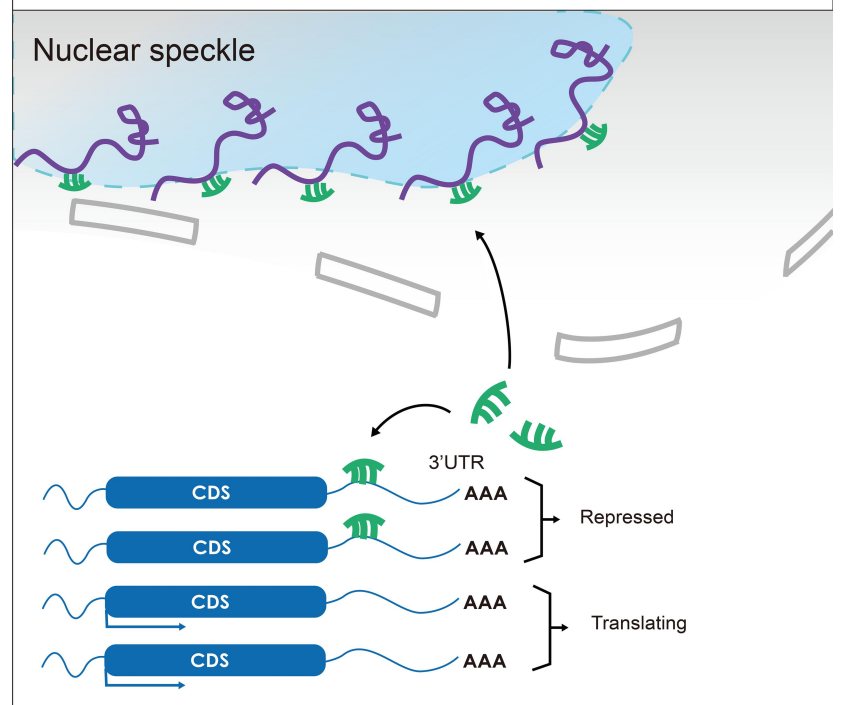

Figure 3 A visual description of Malat I serving as a competing endogenous RNA (ceRNA). While enriched in the nuclear speckles, Malatl can affect the expression of certain mRNAs which share the same MREs by competitively binding with specific microRNAs.

and miRNA are negatively correlated, it is necessary to down-regulate the levels of Malat1 and miRNA at the same time; this will allow us to block the Malat1induced upregulation of miRNA. Only when the levels of an oncogene protein and the related phenotype are both reversed, can it be confirmed that interactions between a specific miRNA and Malat1 can regulate the expression of the given oncogene.

In addition, we should confirm whether the Malat1 IncRNA can be considered as a ceRNA in terms of subcellular localization. ${ }^{87}$ Generally, lncRNAs show enrichment in the cytoplasm when they act as a ceRNA. ${ }^{8,88}$ In part, this is because the miRNA matures in the cytoplasm; ${ }^{89,90}$ this is also the location for interactions between miRNAs and mRNAs. ${ }^{76,89}$ Although many studies have identified that miRNAs perform their duties in the nucleus, ${ }^{90}$ it is important to ascertain whether our target miRNAs can be transported from the cytoplasm to the nucleus and how this process is controlled.

LncRNAs, such as Malat1, are thought to be able to interact with a range of different molecules, except for miRNAs. ${ }^{91,92}$ Since the Malat1 lncRNA is known to be enriched in the nuclear speckles, a site for storing, assembling, and modifying a range of splicing factors, ${ }^{93}$ it is entirely conceivable that Malat1 may bond to some of these splicing factors. This may affect the process of variable splicing and lead to the aberrant expression of some mRNA variants. ${ }^{14,94,95}$ Protein pull-down and RNA immunoprecipitation (RIP) assays, ${ }^{96,97}$ and other related methods, could be useful if we are to validate such hypotheses. Such studies are particularly important as previous studies have not considered how such processes may relate to gynecological cancer.

Furthermore, it is also important that we emphasize the interaction between the Malat1 IncRNA and other molecules that are retained in the nucleus. We should also investigate for associations between Malat1 and DNA, transcription factors, RNA polymerase, chromatin histones, and other nearby functional proteins. Little is known about how such associations may be involved in gynecological cancer.

Future work should also aim to investigate, in the context of gynecology, the upstream molecules that may affect the expression of Malat1, how Malat1 affects potential downstream effectors to create phenotypic changes, and the processes that are involved with the degradation of Malat1. Interestingly, recent data suggest that the Malat1 lncRNA may possess novel tumor suppressive 
properties in certain diseases, ${ }^{98,99}$ whether this is the case for gynecological cancers has yet to be elucidated. Circular RNA has been reported to act as a sponge for miRNA, and also acts as a regulator of protein scaffolding and autophagy to modulate gene splicing, transcription, translation and cell autophagy in hepatocellular cancer. ${ }^{9}$ Therefore, it is important that we investigate the potential role of Malat1 circRNA in gynecological diseases.

\section{Conclusion}

This review discusses the clinical relevance of Malat1 in the context of gynecological cancer and describes our current understanding of the biological functions and mechanisms associated with Malat1. We also highlight a series of action points for future research so that we can fully understand the true potential of Malat1 with regards to clinical diagnosis and treatment.

\section{Acknowledgments}

This research was supported by the Guangdong Academy of Traditional Chinese Medicine. The authors wish to thank Swei Sunny Hann and Huiyi Zhou for their helpful comments on the manuscript.

\section{Disclosure}

The authors have no conflicts of interest to declare.

\section{References}

1. Quinn J, Chang HY. Unique features of long non-coding RNA biogenesis and function. Nat Rev Genet. 2016;17(1):47-62. doi:10.1038/ nrg. 2015.10

2. Ji P, Diederichs S, Wang W, et al. MALAT-1, a novel noncoding RNA, and thymosin beta4 predict metastasis and survival in early-stage non-small cell lung cancer. Oncogene. 2003;22(39):8031-8041. doi:10.1038/sj.onc. 1206928

3. Wilusz JE, Freier SM, Spector DL. 3' end processing of a long nuclear-retained noncoding RNA yields a tRNA-like cytoplasmic RNA. Cell. 2008;135(5):919-932. doi:10.1016/j.cell.2008.10.012

4. Eissmann M, Gutschner T, Hammerle M, et al. Loss of the abundant nuclear non-coding RNA MALAT1 is compatible with life and development. RNA Biol. 2012;9(8):1076-1087. doi:10.4161/rna.21089

5. Brown JA, Valenstein ML, Yario TA, et al. Formation of triple-helical structures by the 3'-end sequences of MALAT1 and MENbeta noncoding RNAs. Proc Natl Acad Sci U S A. 2012;109(47):19202-19207. doi:10.1073/pnas.1217338109

6. Ageeli AA, McGovern-Gooch KR, Kaminska MM, et al. Finely tuned conformational dynamics regulate the protective function of the lncRNA MALAT1 triple helix. Nucleic Acids Res. 2019;47 (3):1468-1481. doi:10.1093/nar/gky1171

7. Nguyen TM, Kabotyanski EB, Reineke LC, et al. The SINEB1 element in the long non-coding RNA Malat1 is necessary for TDP-43 proteostasis. Nucleic Acids Res. 2020;48(5):2621-2642. doi:10.1093/ nar/gkz1176

8. Chen LL. Linking long noncoding RNA localization and function. Trends Biochem Sci. 2016;41(9):761-772. doi:10.1016/j.tibs.2016.07.003
9. Chen L, Kong R, Wu C, et al. Circ-MALAT1 functions as both an mRNA translation brake and a microRNA sponge to promote self-renewal of hepatocellular cancer stem cells. Adv Sci (Weinh). 2020;7(4):1900949. doi:10.1002/advs.201900949

10. Zhang H, Li W, Gu W, et al. MALAT1 accelerates the development and progression of renal cell carcinoma by decreasing the expression of miR-203 and promoting the expression of BIRC5. Cell Prolif. 2019;52(5):e12640. doi:10.1111/cpr.12640

11. West JA, Davis CP, Sunwoo H, et al. The long noncoding RNAs NEAT1 and MALAT1 bind active chromatin sites. Mol Cell. 2014;55 (5):791-802. doi:10.1016/j.molcel.2014.07.012

12. Li B, Chen P, Qu J, et al. Activation of LTBP3 gene by a long noncoding RNA (IncRNA) MALAT1 transcript in mesenchymal stem cells from multiple myeloma. J Biol Chem. 2014;289 (42):29365-29375. doi:10.1074/jbc.M114.572693

13. Qu D, Sun WW, Li L, et al. Long noncoding RNA MALAT1 releases epigenetic silencing of HIV-1 replication by displacing the polycomb repressive complex 2 from binding to the LTR promoter. Nucleic Acids Res. 2019;47(6):3013-3027. doi:10.1093/ nar/gkz117

14. Tripathi V, Ellis JD, Shen Z, et al. The nuclear-retained noncoding RNA MALAT1 regulates alternative splicing by modulating SR splicing factor phosphorylation. Mol Cell. 2010;39(6):925-938. doi:10.1016/j.molcel.2010.08.011

15. Hosseini ES, Meryet-Figuiere M, Sabzalipoor H, et al. Dysregulated expression of long noncoding RNAs in gynecologic cancers. Mol Cancer. 2017;16(1):107. doi:10.1186/s12943-017-0671-2

16. Atianand MK, Caffrey DR, Fitzgerald KA. Immunobiology of long noncoding RNAs. Аnпи Rev Immunol. 2017;35:177-198. doi:10.1146/annurev-immunol-041015-055459

17. Liu W, Venugopal S, Majid S, et al. Single-cell RNA-seq analysis of the brainstem of mutant SOD1 mice reveals perturbed cell types and pathways of amyotrophic lateral sclerosis. Neurobiol Dis. 2020;141:104877. doi:10.1016/j.nbd.2020.104877

18. Sallam T, Sandhu J, Tontonoz P. Long noncoding RNA discovery in cardiovascular disease: decoding form to function. Circ Res. 2018;122(1):155-166. doi:10.1161/CIRCRESAHA.117.311802

19. Yan Y, Song D, Song X, et al. The role of lncRNA MALAT1 in cardiovascular disease. IUBMB Life. 2019.

20. Abdulle LE, Hao JL, Pant OP, et al. MALAT1 as a diagnostic and therapeutic target in diabetes-related complications: a promising long-noncoding RNA. Int $J$ Med Sci. 2019;16(4):548-555. doi:10.7150/ijms.30097

21. Xiong $\mathrm{L}, \mathrm{Wu} \mathrm{L}$, $\mathrm{Li} \mathrm{J}$, et al. LncRNA-Malat1 is involved in lipotoxicity-induced beta-cell dysfunction and the therapeutic effect of exendin-4 via Ptbp1. Endocrinology. 2020;161. doi:10.1210/ endocr/bqaa065

22. Huang H, Sun J, Sun Y, et al. Long noncoding RNAs and their epigenetic function in hematological diseases. Hematol Oncol. 2019;37(1):15-21. doi:10.1002/hon.2534

23. Amodio N, Stamato MA, Juli G, et al. Drugging the lncRNA MALAT1 via LNA gapmeR ASO inhibits gene expression of proteasome subunits and triggers anti-multiple myeloma activity. Leukemia. 2018;32(9):1948-1957. doi:10.1038/s41375-018-0067-3

24. Riva P, Ratti Venturin M, Venturin M. The long non-coding RNAs in neurodegenerative diseases: novel mechanisms of pathogenesis. Curr Alzheimer Res. 2016;13(11):1219-1231. doi:10.2174/ 1567205013666160622112234

25. Wang Y, Gu XX, Huang HT, et al. A genetic variant in the promoter of lncRNA MALAT1 is related to susceptibility of ischemic stroke. Lipids Health Dis. 2020;19(1):57. doi:10.1186/ s12944-020-01236-4

26. Wu Y, Huang C, Meng X, et al. Long noncoding RNA MALAT1: insights into its biogenesis and implications in human disease. Curr Pharm Des. 2015;21(34):5017-5028. doi:10.2174/ 1381612821666150724115625 
27. Groeneweg KE, Au YW, Duijs J, et al. Diabetic nephropathy alters circulating long noncoding RNA levels that normalize following simultaneous pancreas-kidney transplantation. Am J Transplant. 2020;20:3451-3461. doi:10.1111/ajt.15961

28. Koh WJ, Abu-Rustum NR, Bean S, et al. Cervical cancer, version 3.2019, NCCN clinical practice guidelines in oncology. J Natl Compr Canc Netw. 2019;17(1):64-84. doi:10.6004/jncen.2019.0001

29. Bray F, Ferlay J, Soerjomataram I, et al. Global cancer statistics 2018: GLOBOCAN estimates of incidence and mortality worldwide for 36 cancers in 185 countries. CA Cancer J Clin. 2018;68 (6):394-424. doi:10.3322/caac.21492

30. Zhang J, Liu SC, Luo XH, et al. Exosomal long noncoding RNAs are differentially expressed in the cervicovaginal lavage samples of cervical cancer patients. J Clin Lab Anal. 2016;30(6):1116-1121. doi:10.1002/jcla.21990

31. Yang L, Bai HS, Deng Y, et al. High MALAT1 expression predicts a poor prognosis of cervical cancer and promotes cancer cell growth and invasion. Eur Rev Med Pharmacol Sci. 2015;19(17):3187-3193.

32. Zhu P, Wang FQ, Li QR. Correlation study between long non-coding RNA MALAT1 and radiotherapy efficiency on cervical carcinoma and generation of radiotherapy resistant model of cancer. Eur Rev Med Pharmacol Sci. 2018;22(16):5140-5148. doi:10.26355/ eurrev_201808_15709

33. Prat J. New insights into ovarian cancer pathology. Ann Oncol. 2012;23(Suppl 10):x111-x117. doi:10.1093/annonc/mds300

34. Jelovac D, Armstrong DK. Recent progress in the diagnosis and treatment of ovarian cancer. CA Cancer J Clin. 2011;61 (3):183-203. doi:10.3322/caac.20113

35. Lheureux S, Gourley C, Vergote I, et al. Epithelial ovarian cancer. Lancet. 2019;393(10177):1240-1253. doi:10.1016/S0140-6736(18) 32552-2

36. Lin Q, Guan W, Ren W, et al. MALAT1 affects ovarian cancer cell behavior and patient survival. Oncol Rep. 2018;39(6):2644-2652. doi:10.3892/or.2018.6384

37. Qiu JJ, Lin XJ, Tang XY, et al. Exosomal metastasis associated lung adenocarcinoma transcript 1 promotes angiogenesis and predicts poor prognosis in epithelial ovarian cancer. Int J Biol Sci. 2018;14 (14):1960-1973. doi:10.7150/ijbs.28048

38. Chen Q, Su Y, He X, et al. Plasma long non-coding RNA MALAT1 is associated with distant metastasis in patients with epithelial ovarian cancer. Oncol Lett. 2016;12(2):1361-1366. doi:10.3892/ol.2016.4800

39. Eismann J, Heng YJ, Waldschmidt JM, et al. Transcriptome analysis reveals overlap in fusion genes in a Phase I clinical cohort of TNBC and HGSOC patients treated with buparlisib and olaparib. J Cancer Res Clin Oncol. 2020;146(2):503-514. doi:10.1007/s00432-01903078-9

40. Koh WJ, Abu-Rustum NR, Bean S, et al. Uterine neoplasms, version 1.2018, NCCN clinical practice guidelines in oncology. J Natl Compr Canc Netw. 2018;16(2):170-199. doi:10.6004/jnccn.2018.0006

41. Chen G, Zhang M, Liang Z, et al. Association of polymorphisms in MALAT1 with the risk of endometrial cancer in Southern Chinese women. J Clin Lab Anal. 2020;34(4):e23146.

42. Zhao Y, Yang Y, Trovik J, et al. A novel wnt regulatory axis in endometrioid endometrial cancer. Cancer Res. 2014;74 (18):5103-5117. doi:10.1158/0008-5472.CAN-14-0427

43. Meltzer-Gunnes CJ, Smastuen MC, Kristensen GB, et al. Vulvar carcinoma in Norway: a 50-year perspective on trends in incidence, treatment and survival. Gynecol Oncol. 2017;145(3):543-548. doi:10.1016/j.ygyno.2017.03.008

44. Mancini S, Bucchi L, Baldacchini F, et al. Incidence trends of vulvar squamous cell carcinoma in Italy from 1990 to 2015. Gynecol Oncol. 2020;157:656-663. doi:10.1016/j.ygyno.2020.03.013

45. Ni S, Zhao XOuyang L, Ouyang L. Long non-coding RNA expression profile in vulvar squamous cell carcinoma and its clinical significance. Oncol Rep. 2016;36(5):2571-2578. doi:10.3892/ or.2016.5075
46. $\mathrm{Lu} \mathrm{H}, \mathrm{He} \mathrm{Y,} \mathrm{Lin} \mathrm{L,} \mathrm{et} \mathrm{al.} \mathrm{Long} \mathrm{non-coding} \mathrm{RNA} \mathrm{MALAT1} \mathrm{modulates}$ radiosensitivity of HR-HPV+ cervical cancer via sponging miR-145. Tumour Biol. 2016;37(2):1683-1691. doi:10.1007/s13277-015-3946-5

47. Wang N, Hou MS, Zhan Y, et al. MALAT1 promotes cisplatin resistance in cervical cancer by activating the PI3K/AKT pathway. Eur Rev Med Pharmacol Sci. 2018;22(22):7653-7659. doi:10.26355/ eurrev_201811_16382

48. Bai L, Wang A, Zhang Y, et al. Knockdown of MALAT1 enhances chemosensitivity of ovarian cancer cells to cisplatin through inhibiting the Notch1 signaling pathway. Exp Cell Res. 2018;366 (2):161-171. doi:10.1016/j.yexcr.2018.03.014

49. Xu Y, Zhang Q, Lin F, et al. Casiopeina IIgly acts on IncRNA MALAT1 by miR175p to inhibit FZD2 expression via the Wnt signaling pathway during the treatment of cervical carcinoma. Oncol Rep. 2019. doi:10.3892/or.2019.7268

50. Xia C, Liang S, He Z, et al. Metformin, a first-line drug for type 2 diabetes mellitus, disrupts the MALAT1/miR-142-3p sponge to decrease invasion and migration in cervical cancer cells. Eur J Pharm. 2018;830:59-67. doi:10.1016/j.ejphar.2018.04.027

51. Zhang Y, Hu M, Liu L, et al. Anticancer effects of Rosmarinic acid in OVCAR-3 ovarian cancer cells are mediated via induction of apoptosis, suppression of cell migration and modulation of lncRNA MALAT-1 expression. J BUON. 2018;23(3):763-768.

52. Sun R, Qin C, Jiang B, et al. Down-regulation of MALAT1 inhibits cervical cancer cell invasion and metastasis by inhibition of epithelial-mesenchymal transition. Mol Biosyst. 2016;12 (3):952-962. doi:10.1039/C5MB00685F

53. Sun Q, Li QXie F. LncRNA-MALAT1 regulates proliferation and apoptosis of ovarian cancer cells by targeting miR-503-5p. Onco Targets Ther. 2019;12:6297-6307. doi:10.2147/OTT.S214689

54. Shi D, Zhang Y, Lu R, et al. The long non-coding RNA MALAT1 interacted with miR-218 modulates choriocarcinoma growth by targeting Fbxw8. Biomed Pharmacother. 2018;97:543-550. doi:10.1016/j.biopha.2017.10.083

55. Wu HY, Wang XH, Liu K, et al. LncRNA MALAT1 regulates trophoblast cells migration and invasion via miR-206/IGF-1 axis. Cell Cycle. 2020;19(1):39-52. doi:10.1080/15384101.2019.1691787

56. Bedard PL, Hyman DM, Davids MS, et al. Small molecules, big impact: 20 years of targeted therapy in oncology. Lancet. 2020;395 (10229):1078-1088. doi:10.1016/S0140-6736(20)30164-1

57. Aghamiri S, Talaei S, Roshanzamiri S, et al. Delivery of genome editing tools: a promising strategy for HPV-related cervical malignancy therapy. Expert Opin Drug Deliv. 2020;17(6):753-766. doi:10.1080/17425247.2020.1747429

58. Amodio N, Raimondi L, Juli G, et al. MALAT1: a druggable long non-coding RNA for targeted anti-cancer approaches. J Hematol Oncol. 2018;11(1):63. doi:10.1186/s13045-018-0606-4

59. Qadir MI, Bukhat S, Rasul S, et al. RNA therapeutics: identification of novel targets leading to drug discovery. J Cell Biochem. 2020;121 (2):898-929. doi:10.1002/jcb.29364

60. Gong N, Teng X, Li J, et al. Antisense oligonucleotide-conjugated nanostructure-targeting lncRNA MALAT1 inhibits cancer metastasis. ACS Appl Mater Interfaces. 2019;11(1):37-42. doi:10.1021/ acsami.8b18288

61. Hao Y, Yan Z, Zhang A, et al. IL-6/STAT3 mediates the HPV18 E6/ E7 stimulated upregulation of MALAT1 gene in cervical cancer HeLa cells. Virus Res. 2020;281:197907. doi:10.1016/j. virusres.2020.197907

62. Liu S, Song L, Zeng S, et al. MALAT1-miR-124-RBG2 axis is involved in growth and invasion of HR-HPV-positive cervical cancer cells. Tumour Biol. 2016;37(1):633-640. doi:10.1007/s13277-0153732-4

63. Li Y, Ding Y, Ding N, et al. MicroRNA-625-5p sponges lncRNA MALAT1 to inhibit cervical carcinoma cell growth by suppressing NF-kappaB signaling. Cell Biochem Biophys. 2020;78(2):217-225. doi:10.1007/s12013-020-00904-7 
64. Yang L, Lin C, Liu W, et al. ncRNA- and Pc2 methylation-dependent gene relocation between nuclear structures mediates gene activation programs. Cell. 2011;147(4):773-788. doi:10.1016/j.cell.2011.08.054

65. Zou A, Liu R, Wu X. Long non-coding RNA MALAT1 is up-regulated in ovarian cancer tissue and promotes SK-OV-3 cell proliferation and invasion. Neoplasma. 2016;63(6):865-872. doi:10.4149/neo_2016_605

66. Jin Y, Feng SJ, Qiu S, et al. LncRNA MALAT1 promotes proliferation and metastasis in epithelial ovarian cancer via the PI3K-AKT pathway. Eur Rev Med Pharmacol Sci. 2017;21(14):3176-3184.

67. Guo C, Wang X, Chen LP, et al. Long non-coding RNA MALAT1 regulates ovarian cancer cell proliferation, migration and apoptosis through Wnt/beta-catenin signaling pathway. Eur Rev Med Pharmacol Sci. 2018;22(12):3703-3712. doi:10.26355/ eurrev 20180615249

68. Lei $\bar{R}$, Xue $-\mathrm{M}$, Zhang $\mathrm{L}$, et al. Long noncoding RNA MALAT1-regulated microRNA 506 modulates ovarian cancer growth by targeting iASPP. Onco Targets Ther. 2017;10:35-46. doi:10.2147/ OTT.S 112686

69. Tao F, Tian X, Ruan S, et al. miR-211 sponges lncRNA MALAT1 to suppress tumor growth and progression through inhibiting PHF19 in ovarian carcinoma. FASEB J. 2018;fj201800495RR. doi:10.1096/ fj.201800495RR

70. Pa M, Naizaer G, Seyiti A, et al. Long noncoding RNA MALAT1 functions as a sponge of MiR-200c in ovarian cancer. Oncol Res. 2017. doi:10.3727/096504017X15049198963076

71. Gordon MA, Babbs B, Cochrane DR, et al. The long non-coding RNA MALAT1 promotes ovarian cancer progression by regulating RBFOX2-mediated alternative splicing. Mol Carcinog. 2019;58 (2):196-205. doi:10.1002/mc.22919

72. Li Q, Zhang C, Chen R, et al. Disrupting MALAT1/miR-200c sponge decreases invasion and migration in endometrioid endometrial carcinoma. Cancer Lett. 2016;383(1):28-40. doi:10.1016/j. canlet.2016.09.019

73. Lok C, van Trommel N, Massuger L, et al. Practical clinical guidelines of the EOTTD for treatment and referral of gestational trophoblastic disease. Eur J Cancer. 2020;130:228-240. doi:10.1016/j. ejca.2020.02.011

74. Gibb EA, Becker-Santos DD, Enfield KS, et al. Aberrant expression of long noncoding RNAs in cervical intraepithelial neoplasia. Int $J$ Gynecol Cancer. 2012;22(9):1557-1563. doi:10.1097/ IGC.0b013e318272f2c9

75. Kopp F, Mendell JT. Functional classification and experimental dissection of long noncoding RNAs. Cell. 2018;172(3):393-407. doi:10.1016/j.cell.2018.01.011

76. Bartel DP. Metazoan MicroRNAs. Cell. 2018;173(1):20-51 doi:10.1016/j.cell.2018.03.006

77. Yekta S, Shih IH, Bartel DP. MicroRNA-directed cleavage of HOXB8 mRNA. Science. 2004;304(5670):594-596. doi:10.1126/ science. 1097434

78. Deforges J, Reis RS, Jacquet P, et al. Prediction of regulatory long intergenic non-coding RNAs acting in trans through base-pairing interactions. BMC Genom. 2019;20(1):601. doi:10.1186/s12864019-5946-0

79. Hudson W, Ortlund EA. The structure, function and evolution of proteins that bind DNA and RNA. Nat Rev Mol Cell Biol. 2014;15 (11):749-760. doi:10.1038/nrm3884

80. Gezer U, Ozgur E, Cetinkaya M, et al. Long non-coding RNAs with low expression levels in cells are enriched in secreted exosomes. Cell Biol Int. 2014;38(9):1076-1079. doi:10.1002/cbin.10301

81. Nicholas J. A new diagnostic tool with the potential to predict tumor metastasis. J Natl Cancer Inst. 2013;105(6):371-372. doi:10.1093/ jnci/djt048
82. Abramowicz A, Story MD. The long and short of it: the emerging roles of non-coding RNA in small extracellular vesicles. Cancers (Basel). 2020;12(6):1445. doi:10.3390/cancers12061445

83. Ko J, Carpenter EIssadore D, Issadore D. Detection and isolation of circulating exosomes and microvesicles for cancer monitoring and diagnostics using micro-/nano-based devices. Analyst. 2016;141 (2):450-460. doi:10.1039/C5AN01610J

84. Dong J, Su M, Chang W, et al. Long non-coding RNAs on the stage of cervical cancer. Oncol Rep. 2017;38(4):1923-1931. doi:10.3892/ or.2017.5905

85. Salmena L, Poliseno L, Tay Y, et al. A ceRNA hypothesis: the Rosetta Stone of a hidden RNA language? Cell. 2011;146 (3):353-358. doi:10.1016/j.cell.2011.07.014

86. Seitz H. Redefining microRNA targets. Curr Biol. 2009;19 (10):870-873. doi:10.1016/j.cub.2009.03.059

87. Carlevaro-Fita J, Johnson R. Global positioning system: understanding long noncoding RNAs through subcellular localization. Mol Cell. 2019;73(5):869-883. doi:10.1016/j.molcel.2019.02.008

88. Cesana M, Cacchiarelli D, Legnini I, et al. A long noncoding RNA controls muscle differentiation by functioning as a competing endogenous RNA. Cell. 2011;147(2):358-369. doi:10.1016/j. cell.2011.09.028

89. Bartel DP. MicroRNAs: genomics, biogenesis, mechanism, and function. Cell. 2004;116(2):281-297. doi:10.1016/S0092-8674(04) 00045-5

90. Liu H, Lei C, He Q, et al. Nuclear functions of mammalian MicroRNAs in gene regulation, immunity and cancer. Mol Cancer. 2018;17(1):64. doi:10.1186/s12943-018-0765-5

91. Wu J, Hann SS. Functions and roles of long-non-coding RNAs in human nasopharyngeal carcinoma. Cell Physiol Biochem. 2018;45 (3):1191-1204. doi:10.1159/000487451

92. Tang XJ, Wang Hann SS, Hann SS. Interactions among lncRNAs, miRNAs and mRNA in colorectal cancer. Biochimie. 2019;163:58-72. doi:10.1016/j.biochi.2019.05.010

93. Lamond A, Spector DL. Nuclear speckles: a model for nuclear organelles. Nat Rev Mol Cell Biol. 2003;4(8):605-612. doi:10.1038/ nrm 1172

94. Cardamone G, Paraboschi EM, Solda G, et al. Not only cancer: the long non-coding RNA MALAT1 affects the repertoire of alternatively spliced transcripts and circular RNAs in multiple sclerosis. Hum Mol Genet. 2019;28(9):1414-1428. doi:10.1093/hmg/ddy438

95. Meseure D, Vacher S, Lallemand F, et al. Prognostic value of a newly identified MALAT1 alternatively spliced transcript in breast cancer. Br J Cancer. 2016;114(12):1395-1404. doi:10.1038/bjc.2016.123

96. Cipriano A, Ballarino M. The ever-evolving concept of the gene: the use of RNA/protein experimental techniques to understand genome functions. Front Mol Biosci. 2018;5:20. doi:10.3389/ fmolb.2018.00020

97. Barra Leucci E, Leucci E. Probing long non-coding RNA-protein interactions. Front Mol Biosci. 2017;4:45. doi:10.3389/ fmolb.2017.00045

98. Kwok ZH, Roche V, Chew XH, et al. A non-canonical tumor suppressive role for the long non-coding RNA MALAT1 in colon and breast cancers. Int $J$ Cancer. 2018;143(3):668-678. doi:10.1002/ ijc. 31386

99. Kim J, Piao HL, Kim BJ, et al. Long noncoding RNA MALAT1 suppresses breast cancer metastasis. Nat Genet. 2018;50 (12):1705-1715. doi:10.1038/s41588-018-0252-3 


\section{Publish your work in this journal}

Cancer Management and Research is an international, peer-reviewed The manuscript management system is completely online and includes open access journal focusing on cancer research and the optimal use of a very quick and fair peer-review system, which is all easy to use. preventative and integrated treatment interventions to achieve improved Visit http://www.dovepress.com/testimonials.php to read real quotes outcomes, enhanced survival and quality of life for the cancer patient. from published authors.

Submit your manuscript here: https://www.dovepress.com/cancer-management-and-research-journal 